\title{
Video Content Search System for Better Students Engagement in the Learning Process
}

http://dx.doi.org/10.3991/ijet.v9i6.4155

\author{
A. M. Al Otaibi and A. Fayyoumi \\ Al Imam Mohammad ibn Saud Islamic University (IMSIU), Riyadh, Saudi Arabia
}

\begin{abstract}
As a component of the e-learning educational process, content plays an essential role. Increasingly, the video-recorded lectures in e-learning systems are becoming more important to learners. In most cases, a single videorecorded lecture contains more than one topic or sub-topic. Therefore, to enable learners to find the desired topic and reduce learning time, e-learning systems need to provide a search capability for searching within the video content. This can be accomplished by enabling learners to identify the video or portion that contains a keyword they are looking for.
\end{abstract}

This research aims to develop Video Content Search system to facilitate searching in educational videos and its contents. Preliminary results of an experimentation were conducted on a selected university course. All students needed a system to avoid time-wasting problem of watching long videos with no significant benefit. The statistics showed that the number of learners increased during the experiment. Future work will include studying impact of VCS system on students' performance and satisfaction.

Index Terms-Video Search, Educational Video, E-learning Systems.

\section{INTRODUCTION}

The e-learning systems are composed of different components; one important part is the educational content that is delivered through learning management systems (LMSs). In addition to documents, files, presentations, case studies, and interactive learning objects; the recorded lectures and videos are made available for students and are becoming more essential [1].

In recent years, video-recorded lectures in e-learning systems have become increasingly important to learners [2]. Today, worldwide, online repositories contain more than 100 million videos, with an additional 100,000 being uploaded each day [3]. Clearly, this requires learners to spend a great deal of time searching and finding the desired concept in these videos. Therefore, using the search tool for video-recorded lectures can play an important role in student's learning.

Consequently, learners need a fast and accurate searching method that is based on content recognition results to display the portions where the words were actually spoken by the lecturer. A variety of tools exist for searching content in videos [4]. Number of systems allow the users to search in recorded lectures using a search tool that combines a speech-to-text converter with a search engine for video-recorded lectures [2]. Such systems have the advantage of reducing the time needed to find the desired concept in recorded lectures.
This paper presents the developed system and the preliminary results of an experimentation conducted on a selected university course. Future work will study the impact of such tools on students' performance and satisfaction.

\section{Multimedia SEARCH}

Multimedia search and retrieval has become an active research field in the area of education. The increasing use of videos is leading to the need for searching system in video contents. Searching on a content approach can identify the videos or portions from the keyword content of the video list. That is, the search process is performed not on external information but on the words spoken in recorded lectures. However, when performed manually, this technique is difficult and time-consuming [5] .

Currently, some of the search processes for video contents are based on speech recognition [6]. These techniques are used to provide better usability and satisfaction to the user. Nowadays, many applications can significantly benefit from the content based search and retrieval capabilities. Glass et al. [7] developed a project based on text search for video content. In the project they used tools to improve the access to on-line audio/visual recordings of academic lectures by the processing, transcription, indexing, segmentation, summarization, retrieval and browsing this media. Their project called MIT Spoken Lecture Processing Project which contains over 500 hours of Massachusetts Institute of Technology (MIT) lecture recordings, over 200 hours of which have been transcribed. In addition, they developed web-based user interface for searching, retrieving, browsing and viewing spoken lectures. Another system that is called SPEECHBOT and has been developed at Compaq's research laboratories in Cambridge [8]. This system presented an audio and video search engine for multimedia content. Also, it is indexes audio from public Web sites such as Broadcast.com, PBS.org, and InternetNews.com. It used a speech recognition technology and so is able to operate both with and without transcriptions. In addition, this system is able of indexing up to 800 hours of audio per week.

Another application that was developed by Microsoft, called Microsoft Audio Video Indexing Service (MAVIS) [9]. This application enables searching of digitized spoken content, whether they are from meetings, conference calls, voice mails, presentations, online lectures, or even Internet video. In addition, MAVIS has ability to generate automatic closed captions and keywords which can increase accessibility and discoverability of audio and video files with speech content. MAVIS generates a binary file which can be searched in Microsoft SQL server using full text search. Users are able to type in search terms, the 
result is a set of clickable links, will start playing the audio from where those terms were spoken. MAVIS uses Deep Neural Net (DNN) based speech recognition technology to convert audio signals into words. Furthermore, MAVIS reduces errors in speech recognition by automatically expanding its vocabulary, and storing word alternatives using a technique called Probabilistic WordLattice Indexing. The succeeding section provides a detailed view of the Video Content Search (VCS) system that has been developed and experimented to search in educational video content.

\section{VIDEO CONTENT SEARCH SySTEM}

The developed Video Content Search (VCS) system has been developed and was made available to students and instructors to facilitate searching in educational videos. As explained in details later, the experimentation of the system targeted university level students studying the course of Data Mining. The VCS system allows them to play videos and watch the recorded lectures. The videos can be replayed, stopped or played from specific point. More importantly, the VCS system enables users to search for specific keywords - a concept in Data Mining for example- that has been discussed by the instructor during the lecture (the video). Search results allow the user to play only the section of interest instead of watching the complete lecture.

The user interface of the VCS system was designed to let user easily type the text in text-box search and reformulate queries and generally navigate the list of existing videos. The homepage of online VCS System developed for the study in the following figure 1.

The VCS system is a web based system based on MySQL as a database; Java, HTML and JavaScript as development languages. The front end, as shown in figure 1 , allows user to interact with the system queries by typing keywords as text. The backend system focused on the parsing the SRT files in java that interacts with online database in order to store the time by time speeches in the videos.

The database contains real time information about the text being said at particular time (from the SRT file) in addition to other information about videos. The VCS system resides on Java environment. Therefore, when user writes a keyword in search box of the system, a collection of objects with different attributes are shown as a result. These attributes are: description of the video, starting time, ending time and video itself from the position that said by speaker. Also, each of these attributes is stored in the database.

The video stored in the database as compressed compatible format streams. Therefore, when user formulates the query, the text that is specified in the query will be compared with the videotext for each of the videos in the database. Thus, collection of videos will be presented with its attribute and then the user can view the presented videos and play each video clip starting at that point that matches the search condition. See figures 2 and 3.

When the keyword that written by user in search box does not match with any text in all videos in database, the system will show a message to inform the user to reformulate query again. See figure 4.

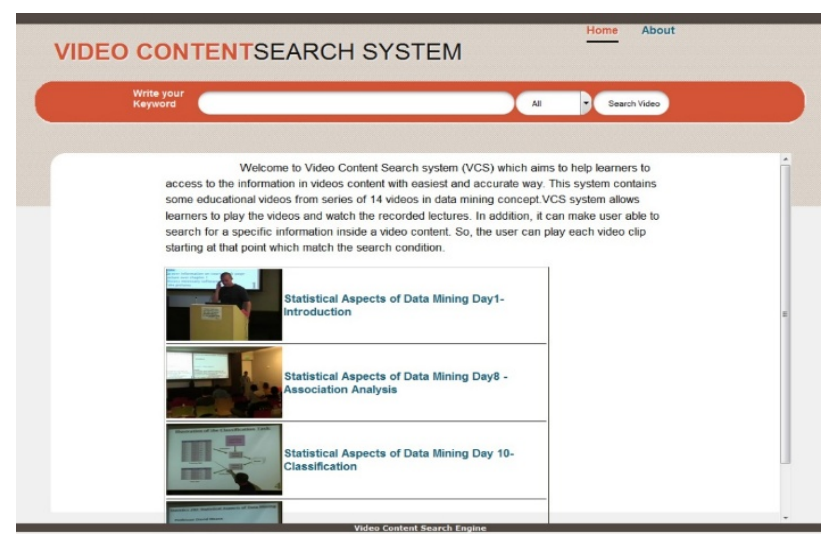

Figure 1. VCS System Homepage

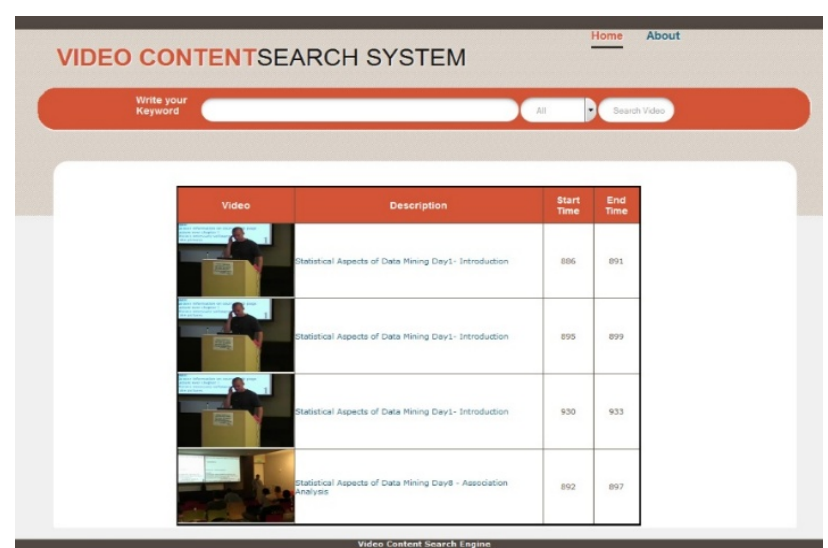

Figure 2. The Result of Query.

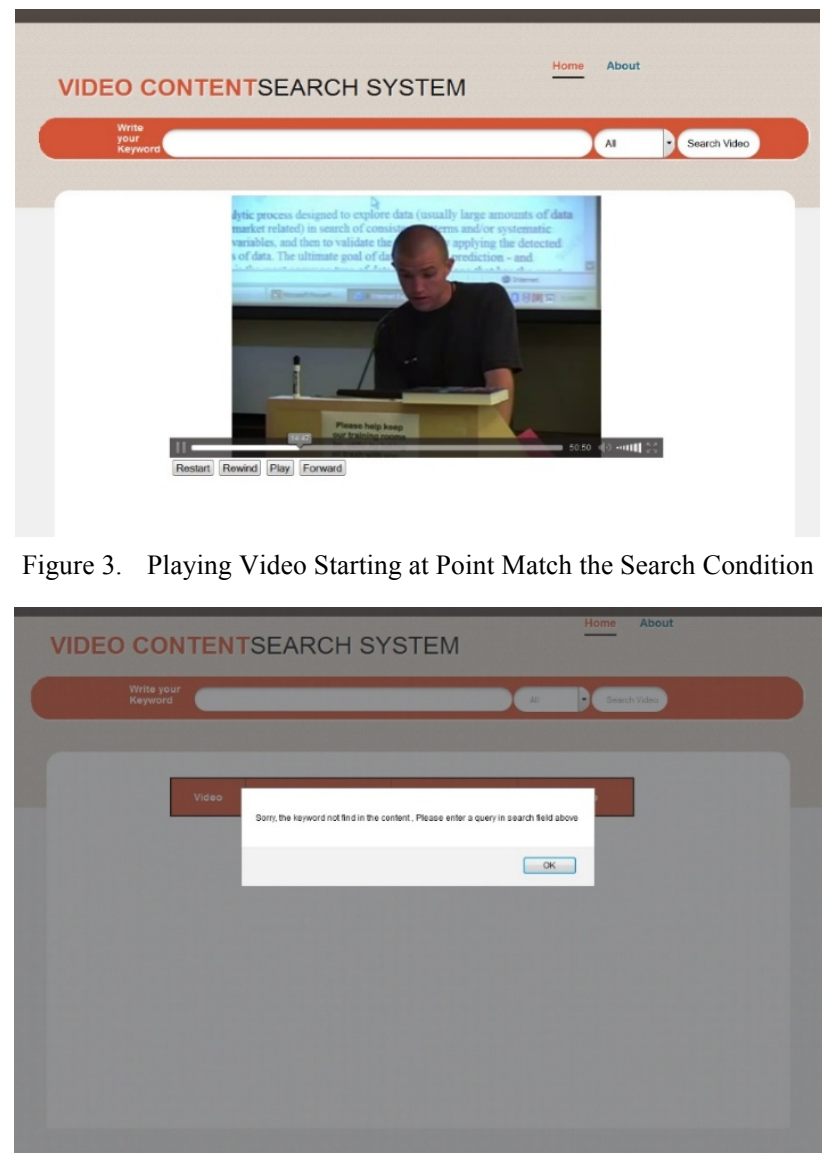

Figure 4. Message Displayed when the Keyword is Not Found 


\section{Methodology}

This paper presents the first phase of the study that aims at understanding the impact of the VCS system on student performance and satisfaction. During the first phase the system has been developed and made available to students for two months. Later on, qualitative data was obtained through structured interviews with university students who are studying Data Mining course to ask them about their impressions and what do they think of the system.

The VCS system was made available through Blackboard at: videoconsearch.com, and it contained educational videos about concepts of Data Mining. The population of this study were regular students in the College of Computer and Information Sciences (CCIS). The college has been using Blackboard system as its supporting platform for the conventional educational process.

The participants accessed the VCS system and used it for one month. Later on, a qualitative data was collected from participants to ask them about their impressions/ Face to face interviews targeted 25 students to ask them about their attitudes toward e-Learning system and what do they think about the VCS system. In addition, the interview gives the researcher flexibility in terms of adapting and changing the questions as the researcher proceeds with the interviews [10]. Table 1 shows some of the questions of the interview.

\section{RESUlTS}

For the purpose of this research study, we will present the results in two sections: results of the interviews, and the results of system usage.

\section{A. Interview Results}

All students have access to Blackboard LMS and visit the blackboard almost each day. They visit Blackboard to get the course materials, submit the assignment and follow announcements. Most teachers used to put links of educational videos on Blackboard. Moreover, the students can search on YouTube to find the educational material.

As they stated, all students agreed that the period of videos is better to be from 10 to 15 minutes. For videos of more than 30 minutes, they don't watch the complete video, instead they move the timeline to forward locations they expect to find what they need. The reasons that prevent students from watching the whole videos was that it is very time consuming considering that it might be a repetition of what they know, or they might not be able to find the information they need very quickly. Most of students faced time-wasting problem after hear videos with long period and they didn't get any benefit from these videos.

Moreover, all students needed a system to solve the problem they faced when they want to watch videos with longer time period. The search capability helped in providing fast access to information, and it is necessary and important for them during their study life. Moreover, students needed a system with shorter educational videos or divided materials to sections in addition to description and title for each video to easily get to understand the objectives.

Students avoid wasting time for single information they need and search for it. Thus, they gain more information while being able to repeat the search process. Moreover, as they stated, the learning process becomes more efficient for them; in addition to that the system will be a reference for them when they need to find explanation for some points that they don't understanding carefully in the lectures.

\section{B. System Usage}

This section describes the statistics about visitors of the VCS system (http://videoconsearch.com). Figure 5 and table II show the summary of visitors who visited the system during the experiment. It shows that the number of learners increased during the experiment, the highest number of visitors was 202 visitors during May, followed by April with 110 learners. In addition, the total number of different visits per page was 2,278 in May and 1,250 in March. Moreover, the number of files downloaded through VCS system reached to 4,098 in May then March with 1,956 files downloaded from the site. The amount of data that has been transmitted across the internet for the web site was presented in the table. So, In May the web site shared with $2.88 \mathrm{~GB}$ for visitors. Moreover, learners have downloaded all videos in the site and used the search engine to find a portion of the videos that they want to review.

TABLE I.

INTERVIEW QUESTIONS

\begin{tabular}{|c|c|}
\hline No. & Interview questions \\
\hline 1 & $\begin{array}{l}\text { Do you have accessibility to Blackboard LMS? How often do } \\
\text { you use it? }\end{array}$ \\
\hline 2 & $\begin{array}{l}\text { During your study, does your instructor used to upload videos? } \\
\text { How long these videos were? }\end{array}$ \\
\hline 3 & $\begin{array}{l}\text { Do you search for educational videos related to courses on the } \\
\text { web? }\end{array}$ \\
\hline 4 & $\begin{array}{l}\text { If the videos were more than one hour long, do you watch it all? } \\
\text { If no, why? }\end{array}$ \\
\hline 5 & $\begin{array}{l}\text { What are the important features that saves your time and make } \\
\text { you benefit more from educational materials? }\end{array}$ \\
\hline 6 & $\begin{array}{l}\text { Are you need a system included all videos about your course } \\
\text { during your study? }\end{array}$ \\
\hline 7 & Did you find the search feature in videos useful? \\
\hline 8 & $\begin{array}{l}\text { To what extent do you think that using search system in video } \\
\text { content will enhance your performance? }\end{array}$ \\
\hline 9 & $\begin{array}{l}\text { Do you think that applying search system in video content will } \\
\text { be helpful to enhance your grades? }\end{array}$ \\
\hline
\end{tabular}

TABLE II.

MONTHLY HISTORY OF ENTRANCE VCS SITE

\begin{tabular}{||c|c|c|c|c|c|}
\hline Month & $\begin{array}{l}\text { Unique } \\
\text { visitors }\end{array}$ & $\begin{array}{c}\text { Number } \\
\text { of visits }\end{array}$ & Pages & Hits & Bandwidth \\
\hline \hline Mar 2014 & 96 & 123 & 1,250 & 1,956 & $830.53 \mathrm{MB}$ \\
\hline \hline Apr 2014 & 110 & 123 & 882 & 1,455 & $2.05 \mathrm{~GB}$ \\
\hline \hline May 2014 & 202 & 219 & 2,278 & 4,098 & $2.88 \mathrm{~GB}$ \\
\hline
\end{tabular}

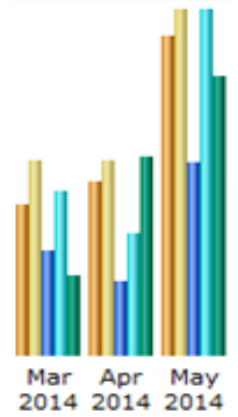

Figure 5. Monthly history of entrance VCS site. 
Table III describes the ways the visitors used to connect to the site in May. The table show that $99.4 \%$ from the visitors used a direct address to enter to the site. As discussed earlier, the sample of this study can visit the Data Mining page on Blackboard and visit the VCS site directly. Also, there is small percentage visits the site by the links from other external pages.

In addition, learners used different browsers when access the site. The table IV shows top browser types that the learners used when connect to the site. The table show that the top three web browser used in the study during the experiment were Firefox with $38.2 \%$, Google Chrome by $36.1 \%$ and Safari that reached to $38 \%$.

\section{CONCLUSION AND FUtURE WORK}

This paper presented the developed system and the preliminary results of an experimentation conducted on a selected university course. Most of students faced timewasting problem after watching long videos. All student stated that they need a system to solve the problem they faced when they want to watch videos with longer time period. The developed system allow them to search in videos by typing keywords as text. It allows them to play videos and watch the recorded lectures. Search results allow the user to play only the section of interest instead of watching the complete lecture.

In addition, some statistics about visitors of the VCS system has been presented. It shows that that the number of learners/visitors increased through time. The highest number of visitors was 202 visitors during May, followed by April with 110 learners. In addition, the learners downloaded all videos from the site and used the search engine to find a portion of the videos that they want to review. The current version of the system supports only numbers of videos on Data Mining concepts, however, more videos can be added in the future.

Future work will study the impact of the developed system on students' performance and satisfaction. Research model will developed to study the impacting factors when the VCS system is used by the learners.

\section{REFERENCES}

[1] D. Zhang, L. Zhou, R. O. Briggs, and J. F. Nunamaker, "Instructional video in e-learning: Assessing the impact of interactive video on learning effectiveness," Information \& Management, vol. 43, no. 1, pp. 15-27, Jan. 2006. http://dx.doi.org/10.1016/j.im.2005.01.004

[2] N. Vivekananthamoorthy, S. Sankar, R. Siva, and S. Sharmila, "An effective E-learning framework model - a case study," 2009 7th International Conference on ICT and Knowledge Engineering, pp. 8-14, Dec. 2009.

[3] C. Lalonde, "MIT Lecture Browser- text search for video content," 2008. [Online]. Available: http://clintlalonde.net/2008/ 01/26/mit-lecture-browser-text-search-for-video-content/.

[4] J. Meng, J. Zhang, and H. Zhao, "Overview of the Speech Recognition Technology," in 2012 Fourth International Conference on Computational and Information Sciences, 2012, pp. 199-202. http://dx.doi.org/10.1109/ICCIS.2012.202

[5] V. K. Kamabathula and S. Iyer, "Automated Tagging to Enable Fine-Grained Browsing of Lecture Videos," 2011 IEEE International Conference on Technology for Education, pp. 96102, Jul. 2011. http://dx.doi.org/10.1109/T4E.2011.23
TABLE III.

CONNECT TO THE SITE IN MAY MONTH

\begin{tabular}{|l|c|c|c|c|}
\hline \multicolumn{1}{|c|}{ Origin } & Pages & Percent & Hits & Percent \\
\hline $\begin{array}{l}\text { Direct address / Book- } \\
\text { mark / Link in email. }\end{array}$ & 300 & $96.7 \%$ & 1,737 & $99.4 \%$ \\
\hline $\begin{array}{l}\text { Links from an Internet } \\
\text { Search Engine }\end{array}$ & 1 & $0.3 \%$ & 1 & $0 \%$ \\
\hline $\begin{array}{l}\text { links from an external } \\
\text { page (other web sites } \\
\text { except search engines) }\end{array}$ & 9 & $2.9 \%$ & 9 & $0.5 \%$ \\
\hline
\end{tabular}

TABLE IV.

TOP BROWSER TYPES THAT THE LEARNERS USED.

\begin{tabular}{|l|l|l|}
\hline \multicolumn{1}{|c|}{ March } & \multicolumn{1}{c|}{ April } & \multicolumn{1}{c|}{ May } \\
\hline Firefox: $38.2 \%$ & Chrome: $36.1 \%$ & Safari: 38 \% \\
\hline Chrome: $36.4 \%$ & Firefox: $24.6 \%$ & $\begin{array}{l}\text { iPhone (PDA/Phone browser) } \\
: 19.7 \%\end{array}$ \\
\hline $\begin{array}{l}\text { Internet Explorer: } \\
10.3 \%\end{array}$ & Safari: $14.8 \%$ & $\begin{array}{l}\text { Android browser (PDA/Phone } \\
\text { browser) }: 17.9 \%\end{array}$ \\
\hline Safari: $9 \%$ & Mozilla: $10.1 \%$ & Chrome : $13.8 \%$ \\
\hline $\begin{array}{l}\text { iPhone } \\
\text { (PDA/Phone } \\
\text { browser): } 2.2 \%\end{array}$ & $\begin{array}{l}\text { Internet Explorer: } \\
8.2 \%\end{array}$ & Unknown: $6.2 \%$ \\
\hline Mozilla: $1.9 \%$ & Unknown: $4.5 \%$ & Firefox: $1.7 \%$ \\
\hline
\end{tabular}

[6] P. Saini and P. Kaur, "Automatic Speech Recognition: A Review," International Journal of Engineering Trends and Technology, vol. 4, no. iii, pp. 132-136, 2013.

[7] J. Glass, T. Hazen, and S. Cyphers, I. Malioutov ,D. Huynh and R. Barzilay "Recent progress in the MIT spoken lecture processing project", pp. 2553-2556, 2007.

[8] J. Van Thong, P. Moreno, B. Logan, F. Blair, M. Katrina, and M. Matthew, "Speechbot: an experimental speech-based search engine for multimedia content on the web", July, 2002.

[9] G. Cheng, B. Chitsaz, G. Li, and F. Seide, "MAVIS," 2012. [Online]. Available: http://research.microsoft.com/en-us/projects/ mavis/. [Accessed: 17-Aug-2013].

[10] I. Seidman, Interviewing as Qualitative Research: A Guide for Researchers in Education and the Social Sciences. NY, 3rd Ed. New York, Teacher College Press, 2006.

\section{AUTHORS}

A. M. AlOtaibi is a teaching assistant at the Information Systems Department, and she is at the final stage of her Master degree in Information Systems (e-mail: amdotaibi@ ccis.imamu.edu.sa).

A. Fayyoumi is an Assistant Professor of Information Systems at the College of Computer and Information Sciences. His research focuses on e-Learning, online exam systems, knowledge management, and e-Business. He is the head of the Scientific Advisory Committee responsible for improving courses contents according to international scientific and quality standards, and a member of the Quality Assurance Committee responsible for ABET accreditation. He also provides different consultation services to various institutions (e-mail: a.fayyoumi@gmail.com)

Submitted 08 September 2014. Published as resubmitted by the authors 08 December 2014. 